\title{
Design de Superfícies: o panorama do ensino no Brasil
}

\author{
Surfaces Design: the prospect of education in Brazil
}

\author{
Marcia Luiza França da Silva \\ marciafranca.designer@gmail.com \\ Marizilda dos Santos Menezes \\ marizilda.menezes@gmail.com
}

\section{Resumo}

O Design de Superfícies (DS), proposto como especialidade do Design em 2005, ainda possui incipiente oferta de ensino. Esta tarefa vem sendo feita por cursos lato sensu na região sul-sudeste do Brasil. A proposta do CNPq sistematizou um conjunto de conhecimentos dispersos em técnicas diversas, cujo título, no plural, reúne várias superfícies e suportes. O objetivo deste artigo é demonstrar o estado da arte do ensino do DS no Brasil, sendo uma parte da pesquisa de um doutorado. A metodologia utilizada foi classificar palavras de busca para identificar áreas interdisciplinares, como Artes Visuais, Design Gráfico, Design de Moda, Design de Produto, dentre outras, para procura de dados de cursos nos níveis técnico e profissionalizante, superior e pósgraduação, nas bases do PRONATEC, SENAI, SENAC, e-MEC e CAPES em DS. Mapas geográficos demonstraram a atuação das áreas relacionadas e possibilitam vislumbrar seu panorama no país, com expressivo predomínio do eixo Sul-Sudeste.

Palavras Chave: ensino do Design; interdisciplinaridade do Design de Superfícies.

\begin{abstract}
The Surfaces Design (DS), proposed as a Design specialty in 2005, still has an incipient teaching offer. This task has been done by five lato sensu courses in the south-southeast region of Brazil. The CNPq proposal systematized a set of knowledge dispersed in diverse techniques, whose title, in the plural, gathers several surfaces and supports. The purpose of this article is to demonstrate the state of the art of teaching DS in Brazil, being a part of the research of a doctorate. The methodology used was to classify search words that allowed the identification of interdisciplinary areas such as Visual Arts, Graphic Design, Fashion Design, Product Design, among others, to search for data of courses at the technical and vocational levels, superior and postgraduate, at the bases of PRONATEC, SENAI, SENAC, e-MEC and CAPES. Geographic maps demonstrate the performance of DS-related areas and make it possible to glimpse its landscape in the country, with a significant predominance of the South-Southeast axis.
\end{abstract}

Keywords: Design teaching, Surface Design interdisciplinarity. 


\section{Introdução}

O Design de Superfícies (DS) é uma especialidade do Design, proposto em 2005 pelo Comitê Assessor de Design do CNPq (Conselho Nacional de Desenvolvimento Científico e Tecnológico). (CNPq, 2005, p.4).

Design de Superfícies é uma especialidade do Design voltada ao desenvolvimento de produtos cuja superfície é trabalhada desde a estruturação do artefato até sua configuração externa, que confere uma caracterização final do produto, cujo ato de se trabalhar a superfície seja como objeto ou envoltório faz uso das metodologias projetuais do Design, das habilidades de representação gráfica, do ornamento, de práticas comuns às Artes Visuais e ao Design Gráfico, das relações intrínsecas a muitas especialidades, como o Design de Moda e o Design de Interiores. Design de Superfícies torna-se, portanto, um crescimento exponencial sempre que mais estudos apontam novas tendências como os novos suportes tecnológicos, que estando aliados à criatividade incentivam novos trabalhos. Ao se aprofundar em suas abordagens, o DS não está restrito à simplicidade de uma técnica de impressão em um determinado suporte, uma vez que o conhecimento de sua artesania exige hoje pesquisa tecnológica. (SILVA E MENEZES, 2017, p.110).

No Brasil, o DS sempre esteve relacionado à sua origem têxtil ou de estamparia para tecidos, ficando desse modo com uma relação próxima à Moda. Conforme Schwartz (2008) e Rinaldi (2013), as relações com o Design de Superfícies vêm se diversificando, originando novas atuações em equipes interdisciplinares.

Moura (2012, p. 1897) descreve as proximidades do Design:

[...] podemos perceber a existência de 4 (quatro) grupos que apresentam nitidamente as interfaces entre a moda e o design, conforme seguem:

1. O grupo de Design Têxtil e de Vestuário reúne trabalhos de design de moda, design de joias, design têxtil, design de superfície para indústria têxtil e similares;

2. O grupo de Design de Produtos reúne trabalhos de design, materiais e processos de fabricação, design de mobiliário e similares;

3. O grupo de Design Sustentável reúne trabalhos de design e sustentabilidade; design, materiais e processos de fabricação, ecodesign e similares;

4. O grupo de Design para Ambientes Construídos reúne trabalhos para design de interiores, design e ambiente construído, design e arquitetura, design e urbanismo e similares.

Há ainda um quinto grupo - "Design para Meios Eletrônicos e Digitais que reúne trabalhos de design de interface digitais; design de processos interativos e imersivos; design de redes; design de jogos; design de movimentos e similares" (MOURA, 2012, p. 1897). Design de Jogos tem relações com o Design de Superfícies e demonstra um potencial expoente no ensino. Por exemplo, entende-se a tesselação como uma importante técnica difundida nos processos digitais, ao se formar texturas em cenários, personagens e demais objetos.

Esses grupos determinam relações inseparáveis a muitas especialidades, principalmente nas metodologias de desenvolvimento de produtos. Esta situação permite caminhos futuros para o DS, ao abordar tratamentos de superfícies variadas. Assim, aqui neste artigo, o DS estará no plural e para um determinado segmento estará no singular. Deste modo, a especialidade Design de Superfícies engloba o Design de Superfície Têxtil. 
Desde esta proposta do CNPq, há uma baixa produtividade acadêmica nestes últimos 12 anos. A partir de seu estabelecimento no Brasil como prática artesanal, percebe-se que hoje é necessário que se tenha pesquisa tecnológica, uma vez que o Design de Superfícies não se restringe a uma simples técnica de impressão. Este artigo é resultado de uma pesquisa de doutoramento que investigou o status quo do DS no país. Sendo o Design uma atividade projetual de caráter inter e multidisciplinar, há que ter uma interação de vários profissionais e equipes de projeto e uma integração de disciplinas práticas e teóricas.

Sobre esta especialidade, verificam-se nos cursos de graduações, disciplinas eletivas ou de extensão e esparsos temas de TCC. A academia tem uma bibliografia escassa, com monografias, dissertações e teses distribuídas em congressos e programas de pós-graduações. Dentro de outras linhas de pesquisa, o Design de Superfícies vem tendo um crescimento entre os acadêmicos. Um mapa de sua atuação no país permite averiguar que a região Sul predomina. No entanto, essa disseminação vem se estendendo pelas demais regiões do país.

Tendo espaços de estudo reduzidos, o DS requer pesquisas científicas para ampliá-lo e consolidá-lo como especialidade do Design. Tendo uma nova ótica sobre sua dimensão e suas abordagens já discutidas por alguns pesquisadores, entende-se que o Design é capaz de desenvolver novas diretrizes.

Há um panorama de cursos livres espalhados pelo país, em escolas privadas ou de profissionais, em sua maioria na parte têxtil, de estamparia, de ilustrações e recursos digitais. A maior oferta é feita pelos cursos lato sensu que tratam de suas aplicações e quase nunca pela fundamentação do Design. No entanto, o vislumbre de um caminho está na fala de Rinaldi:

Entende-se hoje que o Design de Superfície carrega consigo um novo modo de se perceber o objeto e confere aos produtos valores distintos. Um trabalho cuidadoso, que prioriza a teoria e a prática do Design, alcança novas diretrizes para a obtenção de tecnologia, sustentabilidade e estética funcional. (RINALDI, 2013, p. 2).

Uma parcela deste trabalho cuidadoso pode estar no entendimento, a princípio, do estado da arte do ensino do Design de Superfícies. De acordo com Silva e Menezes,

[...] o DS se apropria das metodologias projetuais, se insere no Design e faz uso de métodos e técnicas para materializar os projetos. A Engenharia contribui com suas práticas laboratoriais e produtivas e a Psicologia tem suas inserções no Design Emocional e Sensorial. (SILVA E MENEZES, 2017, p.31).

Sendo escassos os estudos e as bibliografias sobre o ensino do DS, na ótica de Rinaldi (2013, p.36), "a especialidade destina-se a priorizar a superfície no ato projetual." Se deve ser voltada ao projeto, torna-se pertinente inicialmente, pesquisar o ensino do Design para delinear grades e as relações com o DS.

\section{Metodologia}

A metodologia utilizada para pesquisar o ensino do DS no Brasil foi configurada em: a) definição de critérios de palavras de busca; b) coleta de dados em primários, secundários e terciários; c) análise dos dados e d) elaboração de quadros, tabelas e mapa geográfico demonstrando o estado da arte.

A definição de critérios de seleção para os termos de procura deram-se em quatro referências: a) as fundamentações teóricas e disciplinas do Design, sendo o DS sua especialidade; 
b) as quatro linhas de pesquisa do curso lato sensu em Design de Superfície da UFSM (têxtil, cerâmicos, papéis, produto, novas tecnologias e materiais); c) as áreas do Design, Design Gráfico, Design de Produto, Design de Moda, Artes Visuais, Arquitetura e o próprio Design de Superfícies, existindo em cada uma um "efeito multiplicador de terminologias." (SILVA E MENEZES, 2017, p.37), e d) a aplicação de um brainstorming a fim de formatar um quadro de palavras relacionadas.

Na sequência, foram determinados instrumentos para preenchimentos de dados, baseados em planilhas eletrônicas para montagem do banco de dados. Os dados primários compuseram a pesquisa sobre as modalidades de ensino, as terminologias existentes no Design e as ocorrências nas regiões brasileiras. Os dados secundários foram aqueles que aglutinaram as escolas ofertantes, as modalidades presencial e à distância, a datação de implantações de cursos, e a produção acadêmica. Por fim, os dados terciários reuniram os projetos pedagógicos, as grades curriculares e arquivos pertinentes. Os dados secundários e terciários não constam neste artigo, mas foram importantes para a formatação de tabelas, quadros e mapas geográficos.

O brainstorming foi aplicado a 22 participantes de um grupo de estudo dos autores, em três rodadas: a primeira sobre o entendimento do DS para contextualização da prática. A segunda elencou as áreas do Design que estão relacionadas ao DS e a terceira rodada foram as suas aplicações ou atuações. Os dados resultantes estão demonstrados no quadro de palavras da Figura 1:

Figura 1: Quadro de palavras-chave para busca de dados

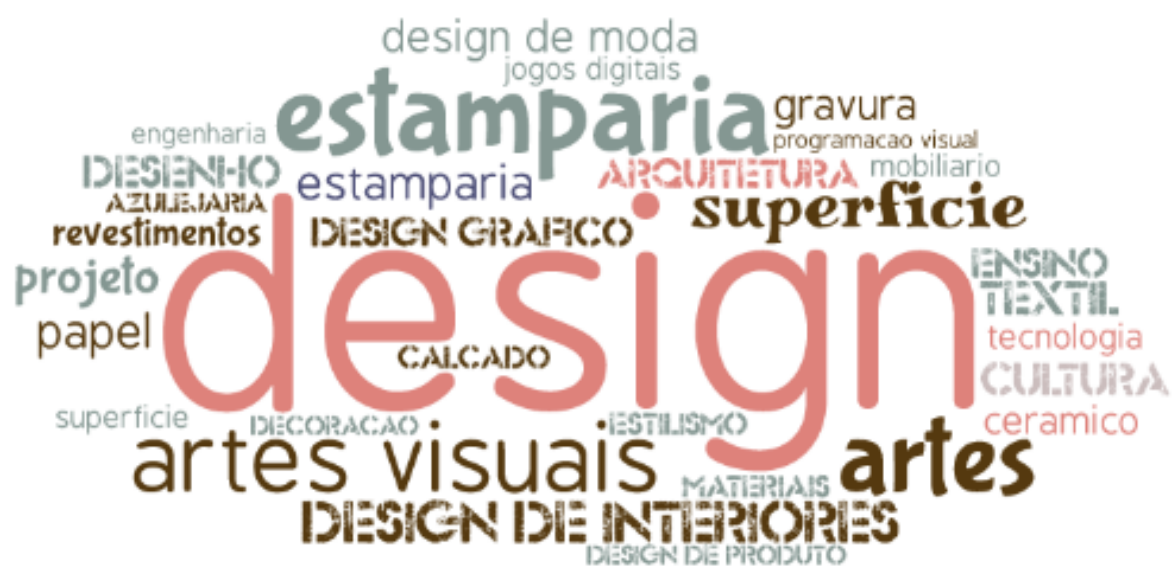

Fonte: Elaborado pelos autores

Foram utilizados os bancos de dados do PRONATEC (Programa Nacional de Acesso ao Ensino Técnico e Emprego), segregando dados referentes às ofertas de cursos técnicos, de acordo com as palavras de busca dispostas na Figura 1. Além disso, SENAl (Serviço Nacional de Aprendizagem Industrial) e SENAC (Serviço Nacional de Aprendizagem Comercial) também foram abordados. O Cadastro da Educação Superior (e-MEC) é uma ferramenta para consulta pública acerca de dados sobre cursos e instituições de educação de nível superior, públicas e privadas. No entanto, o cadastramento das instituições é facultativo, o que pôde comprometer um pouco a contagem de escolas particulares. Nele, foram retirados dados referentes dos cursos de graduação e lato sensu. O sítio da CAPES (Coordenação de Aperfeiçoamento de Pessoal de Nível Superior) mostrou informações sobre os programas stricto sensu. 
O cômputo da coleta gerou informações que mostraram a análise de dados e sua generalidade, assim como a formatação de agrupamentos que podem ser norteadores para o Design de Superfície. Mapas geográficos foram elaborados para que fossem observadas as manchas do estudo no Brasil, assim como verificar possíveis lacunas. O próximo tópico trata do panorama dos dados coletados.

\section{Sobre o ensino do Design de Superfícies}

O panorama do ensino do Design no Brasil permitiu delinear as diversas atuações do DS, bem como o universo de cursos e disciplinas ofertados, e seus respectivos projetos pedagógicos e grades curriculares. Para melhor entendimento, o tópico foi dividido em cursos técnicos e profissionalizantes, educação superior com os cursos de graduação e pós-graduação.

\subsection{Cursos Técnicos e Profissionalizantes}

Existem diferenciações entre um curso técnico e um profissionalizante, e que não se aplicam apenas àqueles voltados sem título de graduação.

Um curso técnico forma profissionais em áreas específicas de atuação, durando de 18 a 24 meses. Seu pré-requisito é a conclusão do ensino médio, mas há outras modalidades que permitem o ingresso, que são: a) integrado (médio é cursado juntamente com o técnico), b) concomitância externa (médio e técnico são cursados paralelamente) e c) subsequente (após o ensino médio e considerado como pós-médio). É conferido um diploma e/ou uma graduação de nível técnico e qualifica o aluno.

Um curso profissionalizante é aquele voltado para um aperfeiçoamento de uma técnica ou ferramenta, durando cerca de seis meses. Confere um certificado e capacita o aluno.

SENAI, SENAC e o PRONATEC são responsáveis por grande parte de cursos técnicos e profissionalizantes no país na área do Design. Reunindo seus dados, ao todo são 286 (duzentos e oitenta e seis) cursos em oferta, em áreas diversas ao universo do Design e Design de Superfícies.

O Design de Moda tem o maior índice das aplicações e em grande incidência, seguido de Design de Móveis e Design Gráfico. Vale lembrar que o Design de Moda envolve todo o setor do vestuário, que Design de Móveis engloba madeira e mobiliário, e o Design Gráfico também se relaciona aos processos de produção e edição de imagens. Materiais tem um número expressivo que agrupou as aplicações relativas a novos materiais, couros e peles, plásticos. Finalmente, o Design Digital refere-se à operação de softwares gráficos. Dados resultantes também mostraram a possibilidade de se delinear uma suposta vocação regional brasileira no DS.

Os dados do SENAI e SENAC são regionais, e do PRONATEC são gerais e estão resumidos nos gráficos da Figura 2. 
Figura 2: Gráfico de aplicações relacionadas ao Design de Superfície

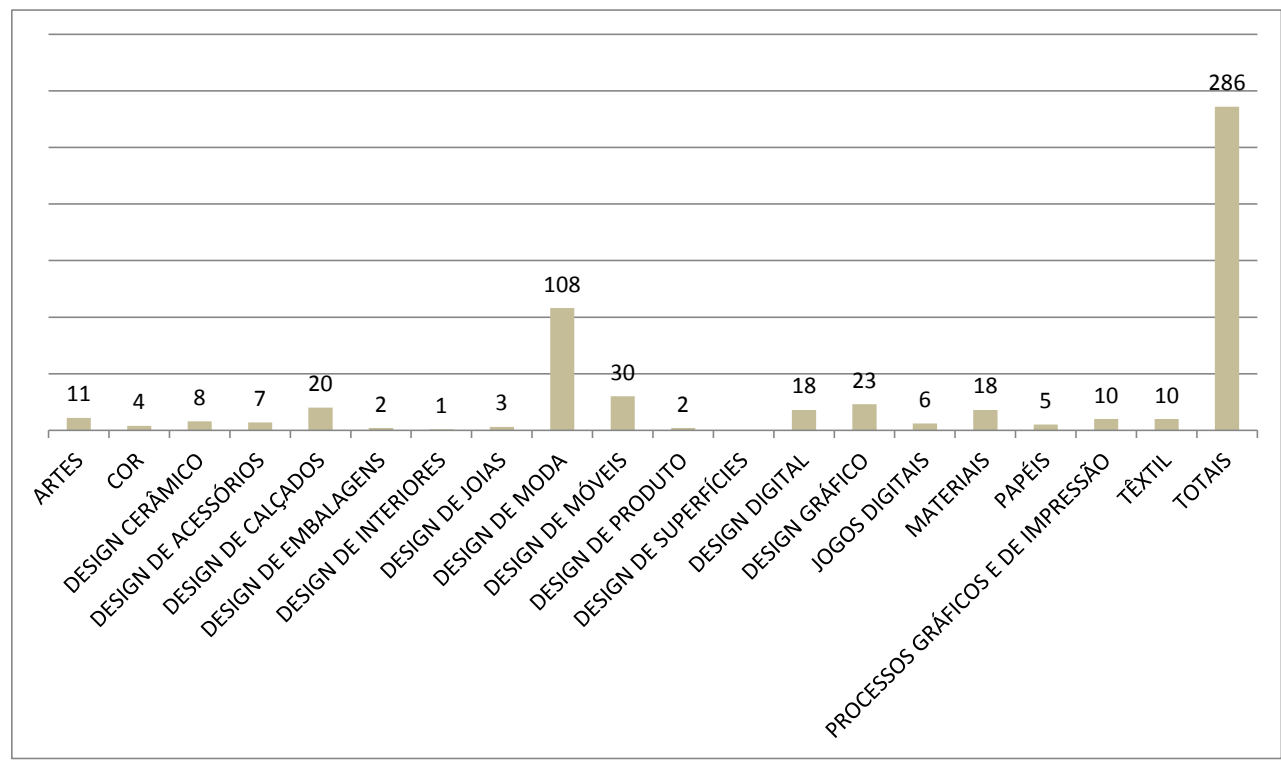

Fonte: elaborado pelos autores

Assim foi composto o Quadro 1, separado por estado e indicando as áreas e/ou aplicações em que os cursos ocorreram.

Quadro 1: Cursos Técnicos e Profissionalizantes em áreas e/ou aplicações do DS

\begin{tabular}{|c|c|c|}
\hline ESTADO & CURSO & ÁREAS E/OU APLICAÇÕES \\
\hline $\mathrm{AP}$ & Marcheteiro & Madeira e mobiliário \\
\hline PA & Técnicas em acabamentos de móveis & Madeira e mobiliário \\
\hline \multirow[t]{2}{*}{$\mathrm{AL}$} & $\begin{array}{l}\text { Ceramista introdução aos processos cerâmicos - processos cerâmicos } \\
\text { revestimento cerâmico }\end{array}$ & Cerâmicos \\
\hline & Técnicas de processamentos plásticos - técnico em plástico & Materiais \\
\hline PB & Desenhista de produtos gráficos & Design gráfico \\
\hline $\mathrm{PI}$ & Auxiliar na fabricação de cerâmica vermelha & Cerâmicos \\
\hline \multirow[t]{2}{*}{ DF } & Pacote adobe para ilustração & Design gráfico \\
\hline & $\begin{array}{l}\text { Artesanato em madeira/MDF - preparação de superfícies para } \\
\text { acabamentos }\end{array}$ & Madeira e mobiliário \\
\hline \multirow[t]{3}{*}{ GO } & Estamparia digital - artesão em bordado à mão & Têxtil \\
\hline & Ilustração digital - ilustrador para pré-impressão & Design gráfico \\
\hline & Operação de processos em fabricação de papel & Papéis \\
\hline \multirow[t]{3}{*}{ MT } & Ferramentas de criação para estamparia em tecido & Têxtil \\
\hline & Artesão de pequenos artefatos de madeira & Madeira e mobiliário \\
\hline & Patchwork & Design de moda \\
\hline MS & Técnico em celulose e papel & Papéis \\
\hline TO & Editor de projeto visual & Design gráfico \\
\hline ES & Desenho de estamparia em CorelDRAW & Têxtil \\
\hline \multirow[t]{2}{*}{ SP } & Técnico de cerâmica & Cerâmicos \\
\hline & Técnico de plásticos & Materiais \\
\hline
\end{tabular}


Continuação do Quadro 1 - Cursos Técnicos e Profissionalizantes em áreas e/ou aplicações do DS

\begin{tabular}{|c|c|c|}
\hline ESTADO & CURSO & ÁREAS E/OU APLICAÇÕES \\
\hline ES & Desenho de estamparia em CorelDRAW & Têxtil \\
\hline SP & $\begin{array}{l}\text { Técnico de cerâmica } \\
\text { Técnico de plásticos }\end{array}$ & $\begin{array}{l}\text { Cerâmicos } \\
\text { Materiais }\end{array}$ \\
\hline PR & $\begin{array}{l}\text { Técnico em celulose e papel } \\
\text { Técnico em plástico } \\
\text { Técnicas manuais - bordado } \\
\text { Superfície de madeira } \\
\text { Programação de bordado computadorizado } \\
\text { Desenvolvimento de estampas em CorelDRAW }\end{array}$ & $\begin{array}{l}\text { Papéis } \\
\text { Materiais } \\
\text { Design de moda } \\
\text { Madeira e mobiliário } \\
\text { Design de moda } \\
\text { Têxtil/ design gráfico }\end{array}$ \\
\hline $\mathrm{SC}$ & $\begin{array}{l}\text { Técnico em cerâmica } \\
\text { Técnico em plástico } \\
\text { Desenvolvimento de artes gráficas para estamparia } \\
\text { Técnicas de estamparia - arte com tecidos - colorimetria } \\
\text { Tecelão em tecidos planos }\end{array}$ & $\begin{array}{l}\text { Cerâmicos } \\
\text { Materiais } \\
\text { Têxtil/design gráfico } \\
\text { Têxtil } \\
\text { Têxtil }\end{array}$ \\
\hline \multirow[t]{4}{*}{ RS } & $\begin{array}{l}\text { Iniciação ao diálogo e harmonia das cores } \\
\text { Básico de matização em semiacabados de couro e outros } \\
\text { materiais } \\
\text { Industrialização de peles e couros } \\
\text { Curtimento e acabamento de peles exóticas } \\
\text { Classificação de couros e peles } \\
\text { Técnico em curtimentos }\end{array}$ & $\begin{array}{l}\text { Design gráfico } \\
\text { Materiais }\end{array}$ \\
\hline & Design de artefatos & Madeira e mobiliário \\
\hline & $\begin{array}{l}\text { Técnica de desenvolvimento de moldes em polímeros } \\
\text { Tecnologias do plástico } \\
\text { Caracterização de termoplásticos }\end{array}$ & Materiais \\
\hline & $\begin{array}{l}\text { Especificação de artefatos de borracha } \\
\text { llustrações artísticas }\end{array}$ & Artes visuais/design gráfico \\
\hline
\end{tabular}

Fonte: elaborado pelos autores

A análise destas informações possibilitou um mapa brasileiro pontuando as possíveis aplicações de cursos e vocações relativas ao Design de Superfícies, demonstrando, na Figura 3, o relativo predomínio da Região Sul nas maiores ocorrências, e o avanço à região Sudeste, CentroOeste e Nordeste.

\subsection{Educação superior}

A Lei de Diretrizes e Bases da Educação Nacional (LDBN - 9394/96) redefiniu os tipos de instituições de ensino superior (IES), de acordo com Álvares (2004). Foram criados: universidade especializada e centros universitários, cursos sequenciais na graduação, mestrados profissionais na pós-graduação e a regulamentação do ensino à distância. 
Figura 3: Mapa de ocorrências de cursos técnicos e profissionalizantes relacionados ao Design de Superfícies - Brasil

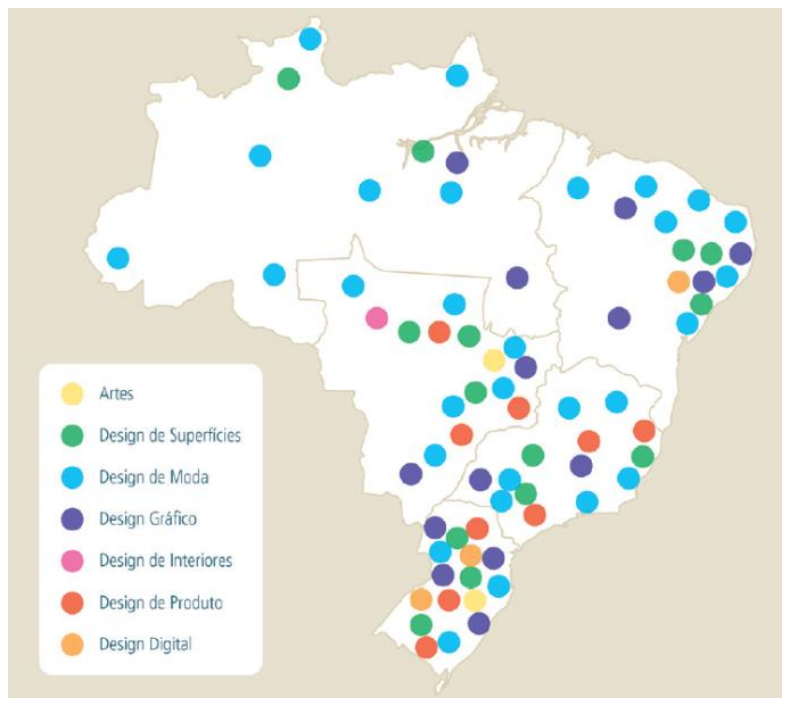

Fonte: elaborado pelos autores

\subsubsection{Graduação}

Para o acesso a um curso de graduação é necessário concluir o ensino médio ou equivalente, além de classificação em processo seletivo. A graduação tem as seguintes modalidades: tradicional, que é cursada numa média de três a seis anos e as disciplinas ofertadas proporcionam um conhecimento mais amplo na área, e com condições para pesquisas científicas. O bacharelado é voltado para se atuar na área técnica. A licenciatura presta-se para atuar na educação. A graduação tecnológica é uma formação que trata de conteúdos voltados ao mercado de trabalho. Com menor tempo de duração, de dois a três anos, forma profissionais para uma atuação em produção e serviços.

Ambas são reconhecidas em todo o país, podendo ser feitas por quem encerrou o Ensino Médio. Também permitem que o egresso possa cursar pós-graduação e prestar concursos para nível superior. Deste modo, existe a possibilidade de se formar uma carreira gradativamente, com a pesquisa científica pela graduação tradicional, ou de atuar rapidamente no mercado.

De acordo com Soares (2002), os cursos sequenciais e de extensão devem estar no mesmo nível dos cursos de graduação. Os cursos sequenciais são aqueles determinados por campo de saber, em níveis diferentes níveis de abrangência, e para candidatos que tenham certificados de nível médio. Também destinam-se àqueles que pretendem obter ou atualizar qualificações técnicas, profissionais, acadêmicas ou intelectuais (nos campos das ciências, humanidades e artes) e possibilitam a obtenção de diploma. (SOARES, 2002, p.50-51).

Os programas de extensão são importantes, uma vez que muitas disciplinas isoladas são administradas por esta via nas universidades, como por exemplo, cursos de Estamparia Digital, Iniciação à llustração, e outros. São cursos abertos à comunidade em geral, e integra atividades de ensino, pesquisa e demandas da população.

A pesquisa no cadastro e-MEC (feita entre janeiro de 2016 a março de 2017) possibilitou o acesso a 1305 (mil trezentos e cinco) cursos de graduação em áreas multidisciplinares ao Design e possivelmente ao Design de Superfícies. Destes, 1001 (mil e um) são presenciais e 304 (trezentos e quatro) à distância. Eles estão distribuídos entre 264 (duzentos e sessenta e quatro) cursos de 
licenciatura, 404 (quatrocentos e quatro) de bacharelado e 637 (seiscentos e trinta e sete) tecnológicos, o que demonstra uma procura mais rápida pelo mercado de trabalho. No gráfico da Figura 4 podem ser vistos os dados de cursos tecnológicos à distância e presenciais.

Figura 4 - Gráfico Quantitativo de cursos tecnológicos à distância e presenciais

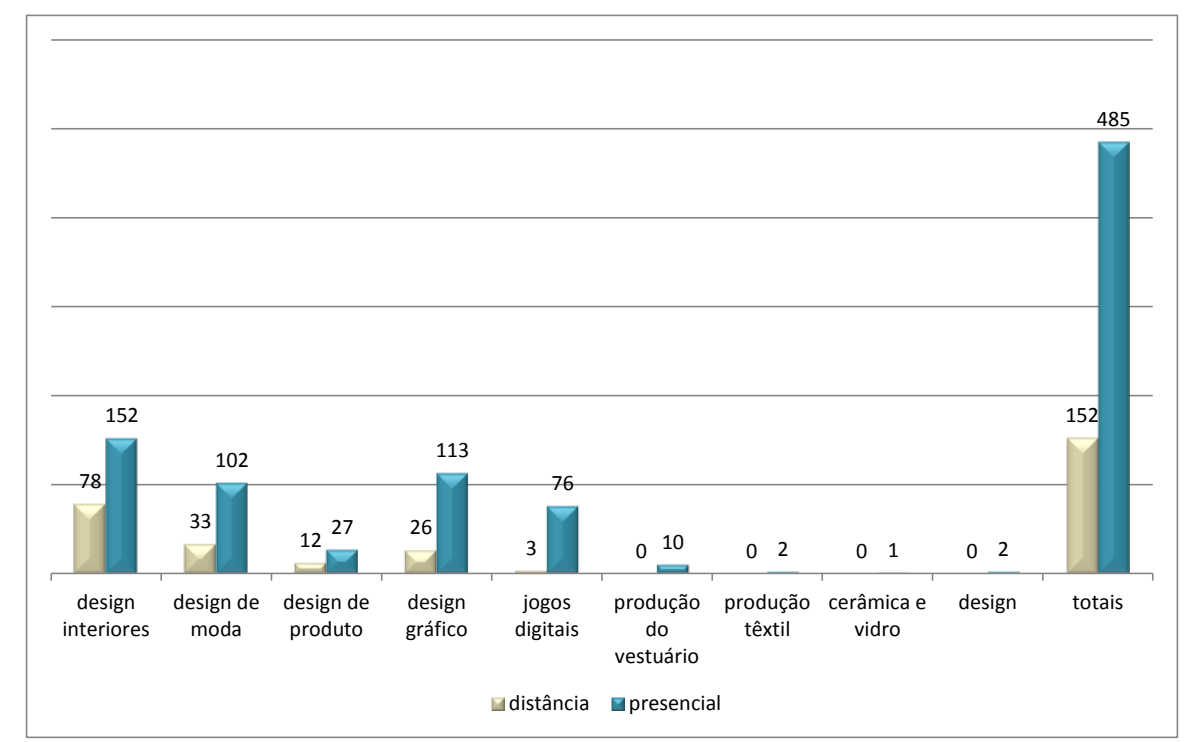

Fonte: Elaborado pelos autores, a partir de dados do e-MEC.

Deve ser observada a expressividade do curso de Jogos digitais, maior do que outras relacionadas ao DS, como o têxtil e próprio Design. São Paulo concentra a maior incidência de cursos e especificamente, com os cursos de Arquitetura, eleva o total da região Sudeste. Sem estes cursos, a região Sul lideraria o ranking, concentrando os três estados que detêm o maior número de cursos. $20 \%$ dos cursos da Região Sudeste contemplam a região Norte. O eixo SulSudeste ainda concentra a interdisciplinaridade do Design, seguido da região Nordeste. Na Figura 5 estão os dados por região brasileira.

Figura 5 - Gráfico da Distribuição dos cursos de graduação multidisciplinares ao DS, por regiões brasileiras

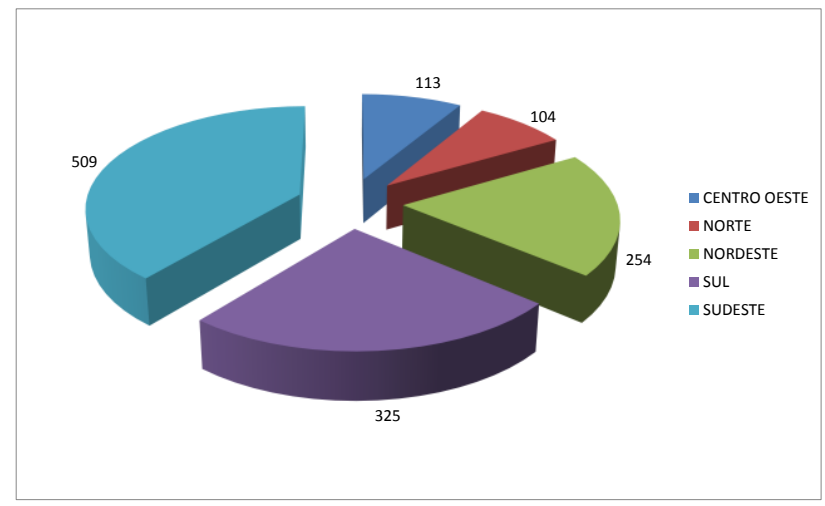

Fonte: Elaborado pelos autores 
Durante as gestões de Luiz Inácio Lula da Silva e Dilma Roussef registra-se a maior incidência de novos cursos (1130), 87\% de todos os cursos multidisciplinares do Design abertos até então (1305), de 2002 a 2016. Em 2009, pelo REUNI, 244 novos cursos foram abertos, e os anos de 2014 e 2015 tiveram 308. Até o término da pesquisa, em 2017, Acre, Tocantins e Mato Grosso não têm cursos ativos presenciais de Design. Os dados primários permitem montar o mapa brasileiro para o ensino superior, de graduação, conforme a Figura 6.

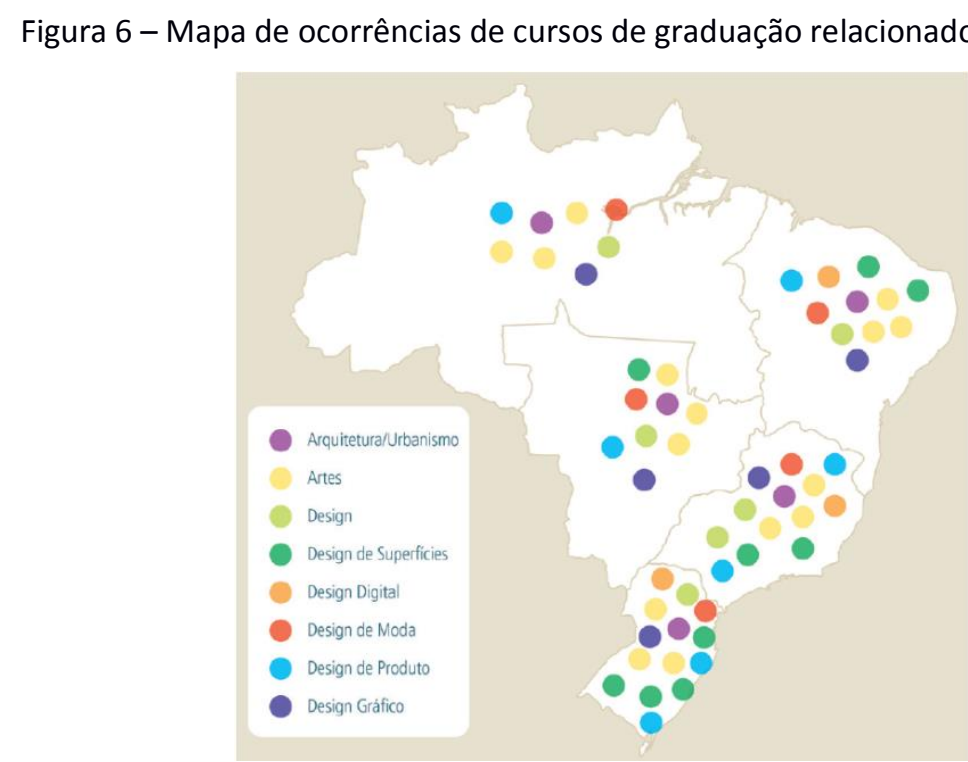

Fonte: Elaborado pelos autores

O gráfico da Figura 7 é relativo aos dados secundários, quanto aos cursos relacionados ao DS.

Figura 7 - Gráfico do Resumo geral de dados de cursos de graduação relacionados ao DS - 2017

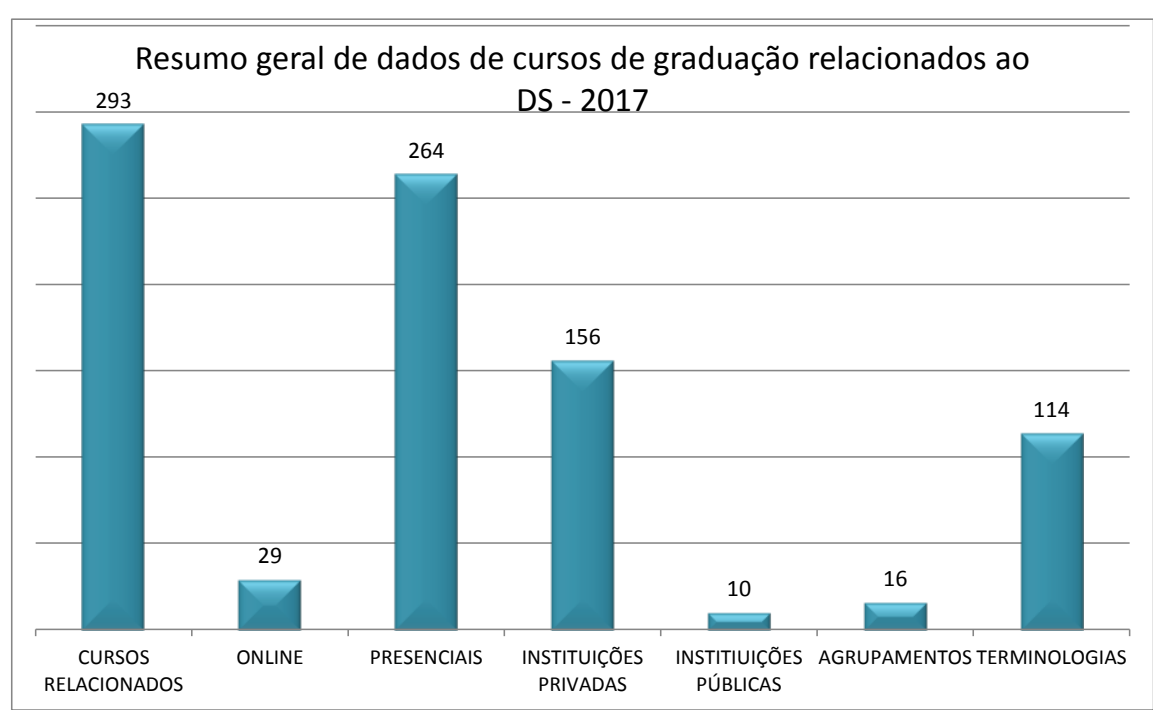

Fonte: Elaborado pelos autores, a partir de dados do e-MEC 
A partir destas informações é possível a procura pelos currículos, projetos pedagógicos e grades para compor os dados terciários, que não são parte deste artigo. A UFSM é a instituição que mais tem disciplinas em Design de Superfícies, pelo Centro de Artes e Letras (CAL), no curso de graduação em Desenho Industrial, com as habilitações de Programação Visual e Projeto de Produto.

\subsubsection{Pós-graduação lato sensu}

No cadastro do e-MEC foi possível a obtenção de dados relativos aos cursos lato sensu, que somaram 114 terminologias de cursos ativos, que foram agrupados, conforme se vê no mapa da Figura 8. No cadastro estão descritos escolas e cursos regulamentados.

Figura 8 - Mapa de ocorrência de cursos lato sensu relacionados ao DS, no Brasil

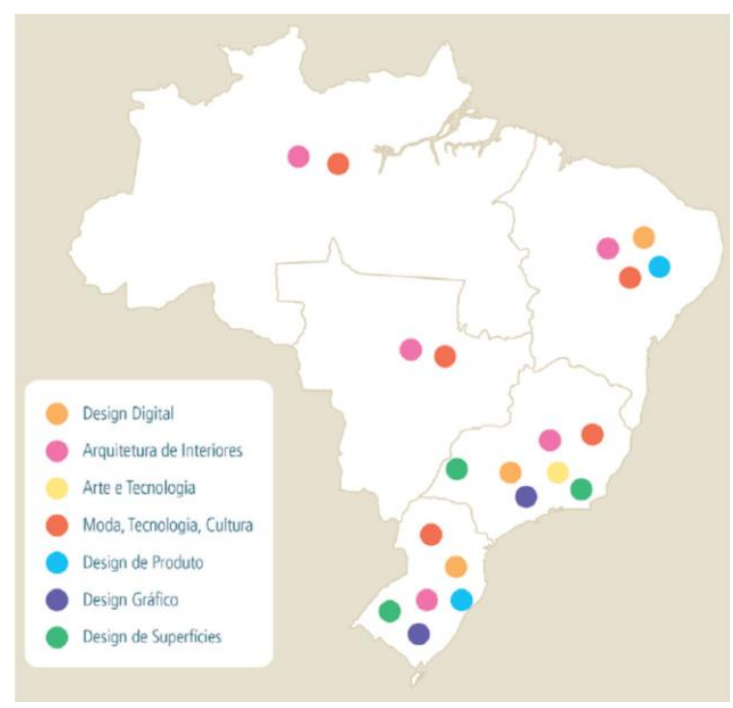

Fonte: Elaborado pelos autores, a partir dos dados do e-MEC.

Em atividade, existem no Brasil cinco cursos lato sensu. O primeiro foi a especialização da Universidade Federal de Santa Maria (UFSM), em 1989, com oferta de 15 vagas. O curso, antes "Especialização em Design para Estamparia", hoje "Especialização em Design de Superfície", tem quatro linhas de pesquisa, de acordo com as aplicações do DS, no têxtil, cerâmico, papéis e outras superfícies, aplicado a produtos, novas tecnologias e materiais.

O curso da UNIRITTER (Centro Universitário Ritter dos Reis) foi o segundo, 23 anos depois, em 2012, com oferta regular de 40 vagas, presencial, na cidade de Porto Alegre. Criou-se em 2015, a especialização da USC-SP (Universidade do Sagrado Coração), com oferta regular de 40 vagas, em Bauru, SP. Em 2016 foi criada a especialização da FEEVALE (Centro Universitário FEEVALE Federação do Estabelecimento de Ensino Superior em Novo Hamburgo - Vale dos Sinos, RS), regular, ofertando 25 vagas. Dentro da pós-graduação em Comunicação e Marketing da FIB Faculdades Integradas de Bauru, SP, está a especialização "Design de Superfície e suas diversas aplicações", datada de 2016.

Verifica-se ainda a existência de outra especialização - "Design em Estamparia" do SENAICETIQT e é específica para a área têxtil. Havia na UNIMEP (Universidade Metodista de Piracicaba, SP) uma especialização desde 2014, - "Design de Superfície com ênfase em Revestimentos 
Cerâmicos" - que em dezembro de 2015, passou a se denominar Design de Superfície, mas atualmente desativada.

Também há o lato sensu em Design de Estampa no SENAI-CETIQT (Serviço Nacional de Aprendizagem Industrial - Centro de Tecnologia da Indústria Química e Têxtil, RJ), do Rio de Janeiro, nome alterado em 2014, antes Design de Estamparia, curso regular com oferta de 20 vagas. Na mesma modalidade há Design Têxtil, Processos e Tecnologia Têxtil.

\subsubsection{Pós-graduação stricto sensu}

Em 1966 foi instalado o primeiro programa em pós-graduação em Design, stricto sensu no país, na Universidade Católica do Rio de Janeiro (PUC-RJ). Foi o começo e estímulo para novos processos de pós-graduação, de acordo com Triska et al (2014, p.71-74) em dados de 2014, com 19 programas em Design no Brasil.

Nenhum destes programas tem, em suas linhas de pesquisa direta, o Design de Superfícies. Algumas investigações foram feitas em linhas relacionadas à moda ou tecnologia, como por exemplo, a UNESP, na linha de pesquisa Planejamento de Produto. O Laboratório do Espaço e da Forma possui defesas de mestrado e doutorado em Design de Superfícies, assim como a UFRGS (Universidade Federal do Rio Grande do Sul). A coleta de dados para cursos stricto sensu foram feitas na CAPES além dos sítios das instituições encontradas.

Foi observado que o total de mestrados profissionais vem superando os acadêmicos, estando separados dos programas mestrado/doutorado. Este aumento crescente talvez esteja alinhado com o crescimento dos cursos tecnológicos de graduação, nos quais o candidato vislumbra a carreira profissional e não a acadêmica. As políticas governamentais, as poucas vagas para professores nas instituições, a não reposição de vagas ociosas e a necessidade do trabalho são fatores que não podem ser deixados de lado nas análises dos dados.

Este cenário tem sua importância para entender uma predominância regional e onde o designer de superfícies pode direcionar suas pesquisas.

No mapa da Figura 9, há a distribuição geográfica de áreas relacionadas ao Design de Superfície em stricto sensu. 
Figura 9 - Mapa brasileiro de ocorrência de cursos stricto sensu relacionados ao DS

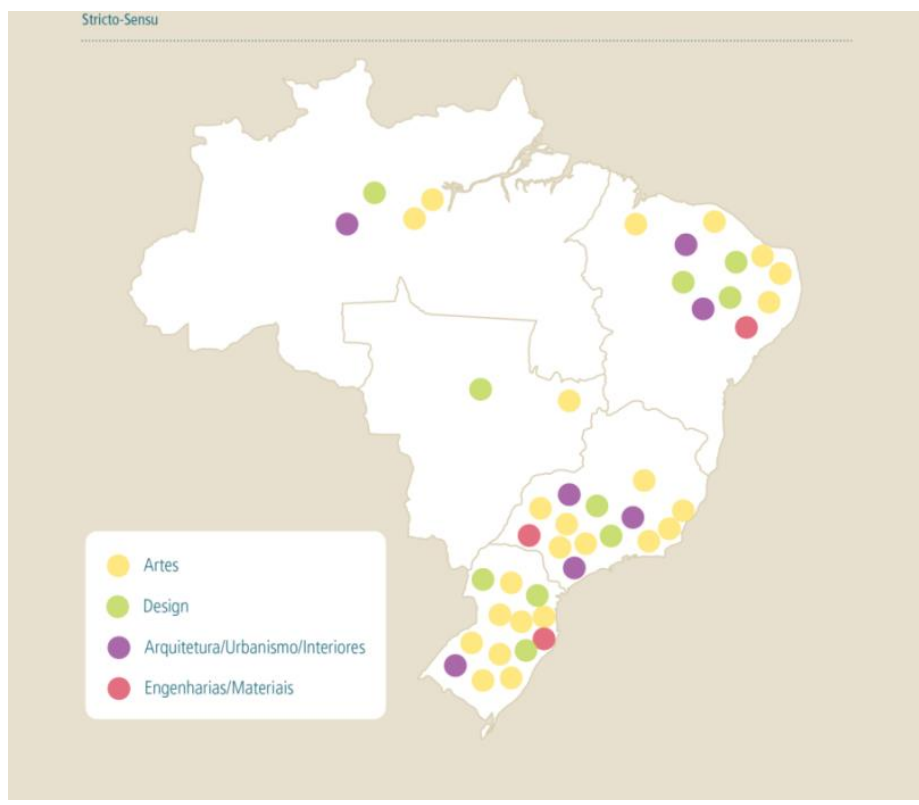

Fonte: Elaborado pelos autores

\section{Conclusão}

O panorama do ensino do Design no Brasil possibilitou uma visão das diversas atuações do Design de Superfícies. O que se observou é que nas escolas privadas ou de profissionais concentram-se os cursos e disciplinas livres, sobre técnicas específicas, em sua grande maioria, estamparia, ilustração e têxtil.

A maior abordagem é feita pelos cursos lato sensu, sendo que tratam especificamente do DS e raramente tratam dos fundamentos do Design. Um trabalho meticuloso deve ser feito que aborde teoria e prática, para se estabelecer premissas para o DS.

PRONATEC, SENAI e SENAC têm expressiva oferta em eixos tecnológicos, distribuídos em cursos relativos ao Design e Design de Superfícies. O Design de Moda tem maior incidência de aplicações.

Foi fundamental o acesso aos cadastros e-MEC), PRONATEC, SENAI, SENAC e CAPES para consulta de dados sobre cursos e instituições de educação de nível superior, públicas e privadas. Mas, alguns dados podem ter alguma inconsistência, pelo fato de ser facultativa a inscrição no $e$ MEC.

Em relação aos cursos superiores, houve o registro de 1305 (mil trezentos e cinco) cursos de graduação em áreas relacionadas ao Design. O eixo Sul-Sudeste concentra o ensino interdisciplinar do Design, assim como avança para a região Nordeste. As regiões Centro-Oeste e Norte possuem um inexpressivo número cursos e de programas de pós-graduação. Devem ser pensadas e realizadas iniciativas em programas para disseminar o Design de Superfícies.

Para os cursos lato sensu, o cadastro e-MEC retornou 114 terminologias de cursos ativos, que foram distribuídos em sete áreas interdisciplinares. Já para o stricto sensu são 20 áreas relacionadas ao DS, com oferta de 98 (noventa e oito cursos), que incluem o Design com 25 
programas, com apenas dois em Moda e Têxtil. Não há nenhuma linha direta em Design de Superfícies, mas verifica-se a existência de algumas teses e dissertações em linhas próximas, nos temas moda, tecnologia e ensino.

O país passa por grandes momentos de dificuldades que entravam a formação de cursos novos em escolas públicas, a contratação de professores e de recursos para infraestrutura, além de expor uma sobrecarga didática aos atuais professores, o que coloca em risco a criação e continuidade de cursos, inclusive lato sensu. O que se nota é a falta de atualização e empenho em pesquisas acadêmicas na área do DS.

Deste modo, o Design de Superfícies vê sua consolidação comprometida, ficando como disciplina livre, de extensão e especialização. Passados 13 anos de seu estabelecimento como disciplinar ao Design, não há ainda linhas de pesquisa específicas nos cursos stricto sensu que poderiam compor um campo crítico na academia. Urge transpor o caminho de disciplinas livres e ocupar lugar de valorização e criticidade.

\section{Referências}

ALVARES, M. R. Ensino do design: a interdisciplinaridade na Disciplina de Projeto em Design. 2004. 163f. Dissertação (Mestrado em Engenharia da Produção) Universidade Federal de Santa Catarina. Florianópolis, 2004.

CAPES. COORDENAÇÃO DE APERFEIÇOAMENTO DE PESSOAL DE NÍVEL SUPERIOR. Plataforma Sucupira. Cursos Stricto Sensu. Disponível em <https://sucupira.capes.gov.br/sucupira/public/consultas/coleta/programa/listaPrograma.jsf> Acesso em 03 jan. 2017.

CNPq - CONSELHO NACIONAL DE DESENVOLVIMENTO CIENTÍFICO E TECNOLÓGICO. Comitê Assessor de Design. 2005. Curitiba: Revisão da tabela de áreas do conhecimento sob a ótica do design. Curitiba: Comitê Assessor de Design/CNPq, 2005.

e-MEC. Cadastro e-MEC: Instituições de Educação Superior e Cursos Cadastrados. Ministério da Educação. Disponível em http://emec.mec.gov.br/ Acesso em 20 Jan. 2016.

MOURA, M. Relações entre a moda e o design. In: 1‥ CIMODE. 1‥ Congresso Internacional de Moda e Design. Anais. Guimarães, Portugal. 2012. pp. 1896-1906.

PGDS. Pós-graduação em Design de Superfície. Universidade Federal de Santa Maria. Disponível em <http://coral.ufsm.br/pgds/index.php/producao/defesas>. Acesso em: 21 Abr 2016.

PRONATEC. REDE FEDERAL DE EDUCAÇÃO TECNOLÓGICA. Catálogo nacional de cursos técnicos do PRONATEC.

Disponível

em

$<$ http://portal.mec.gov.br/index.php?option=com docman\&view=download\&alias=41271-cnct-3edicao-pdf\&category slug=maio-2016-pdf\&ltemid=30192>. Acesso em 05 jan. 2017.

RINALDI, R. M. A intervenção do design nas superfícies projetadas: processos multifacetados e estudos de casos. 2013. 204f. Tese (Doutorado em Design). Faculdade de Artes, Artes e Comunicação, Universidade Estadual Paulista, Bauru, 2013.

SCHWARTZ, A. R. D. Design de superfície: por uma visão geométrica e tridimensional. 2008. $217 f$. Dissertação (Mestrado em Design). Faculdade de Artes, Artes e Comunicação, Universidade Estadual Paulista, Bauru. 2008. 
SENAC - Serviço Nacional de Aprendizagem Comercial. Disponível em <http://www.senac.br/>. Acesso em 16 mar. 2016.

SENAI - Serviço Nacional de Aprendizagem Industrial. Disponível em http://www.portaldaindustria.com.br/senai/. Acesso em 16 mar. 2016.

SENAI-CETIQT - Serviço Nacional de Aprendizagem Industrial. Centro de Tecnologia da Indústria Química e Têxtil, RJ. Disponível em http://senaicetiqt.com/ Acesso em 16 mar. 2016.

SOARES, M.S.A. et al. A educação superior no Brasil. Instituto Internacional para a Educação Superior na América Latina e no Caribe. Porto Alegre: CAPES, 2002.

TRISKA, R.; VELA, J.C.; DOLZAN, J.E. A pós-graduação stricto sensu do Design no Brasil. Revista Estudos em Design. [online]. v.22. n.3. Rio de Janeiro, 2014. pp. 70-80. 